\title{
Por uma teoria da metáfora na interface entre Neurociências e Pragmática
}

\section{For a theory of metaphor on the interface between Neurosciences and Pragmatics}

Kári Lúcia Forneck ${ }^{1}$

Doutoranda em Linguística pelo Program professora do curso de Letras da PUCRS kari@univates.br
RESUMO: Este estudo propõe uma análise das inferências decorrentes de enunciados metafóricos na interface entre Neurociências e Pragmática, para descrição e explicação do processamento inferencial decorrente da compreensão desses enunciados. De um lado, do ponto de vista das Neurociências, via Coarse-code Hypothesis (SHIBATA et al., 2007; EVIATAR e JUST, 2006) e Dynamic Spillover Hypothesis (PRAT et al., 2012), descreveram-se as estruturas corticais recrutadas no processamento da metáfora. De outro, do ponto de vista da Pragmática, via Teoria da Relevância (TR), explicou-se a natureza das inferências decorrentes de enunciados metafóricos pela produção de conceitos ad hoc (WILSON e SPERBER, 2012). Na interface entre essas diferentes disciplinas, evidenciou-se que as inferências produzidas no processamento de enunciados metafóricos podem ser descritas e explicadas, numa perspectiva interdisciplinar, de maneira mais complexa (COSTA, 2007). Desenhou-se, assim, uma abordagem da metáfora cujo potencial descritivo se fundamenta nos achados em Neurociências e cujo potencial explanatório se fundamenta na Pragmática, pela produção dos conceitos ad hoc. Os achados corroboram a tese central pretendida neste estudo, a de que os objetos de investigação, neste caso a metáfora, se desenhados na interface, podem ser descritos e explicados de maneira mais complexa, à medida que propriedades de natureza complexa interagem entre si. Palavras-CHAVE: Metáfora; Neurociências; Teoria da Relevância; Interface Metateórica.

ABSTRACT: This study proposes an analysis of the inferences resulting from metaphorical utterances on the interface between Neuroscience and Pragmatics, for the description and the explanation of the inferential processing resulting from the understanding of these utterances. On the one hand, from the point of view of Neuroscience, via Coarse-code Hypothesis (SHIBATA et al, 2007; EVIATAR and JUST, 2006) and Dynamic Spillover Hypothesis (PRAT et al., 2012), the cortical structures recruited to the metaphor processing have been described. On the other, from the point of view of Pragmatics, via Relevance Theory (RT), the nature of the inferences arising from the production of metaphorical utterances through the production of ad hoc concepts have been explained (WILSON \& SPERBER, 2012). On the interface between these different disciplines, it has been evidenced that the inferences produced in processing metaphorical utterances can be described and explained in an interdisciplinary perspective, in a more complex manner (COSTA, 2007). Thus, we have designed an approach to metaphor, whose descriptive potential is based on the findings of Neuroscience, and whose explanatory potential is based on Pragmatics, through the production of ad hoc concepts. The findings corroborate the central thesis intended in this study, the one in which the objects of investigation, in this case the metaphor, if drawn on the interface, can be described and explained in a more complex manner, as properties of complex nature interact among themselves.

KEYwoRDS: Metaphor; Neuroscience; Relevance Theory; Metatheoretical Interface. 


\section{Considerações iniciais}

definição de uma abordagem teórica para o estudo da metáfora tem-se - guiado fundamentalmente pela tentativa de se descrever e de se explicar de que modo se dá a compreensão de enunciados com metáforas.

Do ponto de vista da Pragmática, os estudos de Grice (1975) configuram-se o ponto de partida para o entendimento dos processos inferenciais em linguagem natural, ainda que não tenham objetivado uma abordagem específica para a metáfora. Na esteira de seus estudos, outros teóricos propuseram abordagens com enfoques distintos, no intuito de elucidarem a metáfora ora nas relações entre Semântica e Pragmática (BERGMANN, 1979; BERGMANN, 1991; DAVIDSON, 1984; MARTINICH, 1991; MILLER, 1979; SEARLE, 1982), ora nas relações entre Pragmática e Ciências Cognitivas (CARSTON, 2002; LAKOFF e JOHNSON, 1980; NOVECK et al., 2001; SPERBER e WILSON, 1986; SPERBER e WILSON, 1991; SPERBER e WILSON, 2008; TENDAHL e GIBBS, 2008; VEGA MORENO, 2004; WILSON e CARSTON, 2006; WILSON e SPERBER, 2012).

Mais recentemente, em razão dos avanços tecnológicos, em especial, pelo acesso à produção de novos dados de pesquisa a partir de ressonâncias magnéticas funcionais (fMRI), por exemplo, aspectos da linguagem humana podem ser revisitados em razão da configuração de novos enfoques disciplinares. É o caso dos estudos em neuroimagem, a partir dos quais têm sido descritas as especificidades do processamento neurológico da linguagem. Esses estudos podem ser configurados tendo como ponto de partida desde o processamento de fonemas, até o processamento discursivo.

Segundo Ferstl (2012), os aspectos contextuais e as intencionalidades do falante, ambos caros a uma abordagem pragmática, configuram-se variáveis complexas nos estudos em neuroimagem, já que deles decorre, por exemplo, o controle das variáveis contextuais de produção dos enunciados e das características cognitivas individuais, como a necessidade de ativação de conhecimentos prévios. Dessa complexa configuração resultam, por exemplo, diferenças no recrutamento de regiões cerebrais tanto no hemisfério esquerdo (HE), quanto no hemisfério direito (HD).

No que diz respeito especificamente ao processamento de enunciados metafóricos, parece haver uma tese consensual: reconhece-se que há maior engajamento do HD na compreensão desses enunciados (cf. FERSTL, 2012, p. 79). Há, entretanto, evidências paradoxalmente distintas em relação à participação do HD na compreensão de metáforas, especialmente se analisadas em textos, diferentemente do processamento de palavras e sentenças simples. Isso se deve, principalmente, porque, no caso de sentenças simples, a não indicação de elementos contextuais resulta em simplificação do processamento neuronal da compreensão. Além do mais, a maioria dos estudos parte do entendimento de que pode haver maior complexidade no processamento de enunciados compostos por metáforas criativas, se comparado ao processamento de metáforas convencionais. Entretanto, a diversidade de achados que se têm à disposição pode ser explicada por diferenças nos procedimentos adotados, nos correlatos neurais analisados e nas concepções teóricas do que são traços semânticos e pragmáticos, por exemplo.

Tanto os estudos em Pragmática quanto os estudos em Neurociências partem da premissa ontológica de que os objetos de investigação são desenhados dentro das fronteiras de cada disciplina. Entretanto, o que se propõe aqui sugere uma abordagem descritiva e explanatória da metáfora, partindo de uma opção metodológica distinta: a de que se pode desenhar os objetos de investigação nas fronteiras entre as disciplinas.

Assim, assume-se a priori que a interface metateórica complexifica a abordagem dos estudos da linguagem, ao desenhar objetos terceiros, nas fronteiras entre as disciplinas, tal como propõe Costa (2007), em 
sua Metateoria das Interfaces. Para tanto, num primeiro momento, serão apresentados estudos em neuroimagem a respeito do processamento da metáfora, a fim de se descreverem os correlatos neurais do processamento desses enunciados; num segundo momento, apresenta-se o modelo pragmático da Teoria da Relevância, opção pragmática aqui adotada, tal como proposto por Sperber e Wilson (1986; 2001; 2008) e Wilson e Sperber (2012), a fim de se explicar a natureza das inferências decorrentes do processamento de enunciados metafóricos. Por fim, no intuito de complexificar o potencial descritivo e explanatório de uma abordagem teórica da metáfora, propõe-se a interface entre as disciplinas em questão.

\section{Das possibilidades descritivas: a anatomia da metáfora no cérebro}

O propósito desta seção é o de apresentar alguns modelos de tratamento da metáfora sob o desenho teórico das neurociências. Inicialmente, convém explicitar que, atualmente, os estudos em neuroimagem acerca da compreensão de metáforas têm se fundamentado, comumente, em duas hipóteses que norteiam as pesquisas em fMRI ${ }^{1}$ :

a) Coarse-code hypothesis: os estudos fundamentados nessa hipótese defendem o argumento de que o HD tem papel fundamental especialmente na compreensão de metáforas criativas, aquelas em que os itens comparados têm poucos traços semânticos em comum. Nesse caso, o HD seria recrutado a fim de se estabelecerem os

\footnotetext{
${ }^{1}$ Há pesquisas que têm se debruçado sobre o papel do HD no processamento da linguagem, a partir da descrição dos correlatos neurais da Theory of mind (ToM). A ToM consiste na habilidade de produzir inferências a respeito do que os outros estão pensando (cf. MASON et al., 2008); por essa razão, com esse escopo, os estudos em neuroimagem baseiam-se no argumento de que o HD (especificamente a junção temporo-parietal superior posterior) é acionado a fim de se reconhecerem as intenções do falante/escritor que podem ser relevantes a compreensão da metáfora, especialmente por levarem em consideração processos pragmáticos e contextuais (cf. SAXE; KANWISHER, 2003). Por não uma opção do processamento da metáfora em si.
}

traços semânticos entre eles. Mais especificamente, ao HD caberiam as funções de acessar as categorias semânticas dos elementos em comparação e selecionar as mais adequadas ao contexto, enquanto ao HE caberia a função de correlacionar os conceitos evocados e integrá-los conceitualmente (cf. FERSTL, 2012, p. 59).

b) Dynamic spillover hypothesis: o HD, de acordo com esta hipótese, é acionado quando a compreensão não for atingida pelo HE. Sob esse paradigma, as individualidades são altamente relevantes (cf. PRAT; MASON; JUST, 2011), já que a compreensão de metáforas, por exemplo, poderá variar dependendo da capacidade e da habilidade linguística de cada indivíduo e do esforço demandado pela tarefa de compreensão.

A seguir apresentam-se três estudos em neuroimagem (SHIBATA et al., 2007; EVIATAR; JUST, 2006; PRAT, MASON; JUST, 2012), a fim de ilustrar de que modo são comumente descritos os elementos corticais recrutados no processamento de metáforas. A opção por esses estudos levou em consideração as hipóteses assumidas e a natureza dos experimentos.

O primeiro estudo é descrito em Shibata et al. (2007), no qual se apresenta um roteiro descritivo dos correlatos neurais para o processamento de metáforas em japonês. Esse estudo, que se deteve no nível da sentença ${ }^{2}$, partiu de duas premissas apresentadas em trabalhos prévios: a) os substratos neurais envolvidos na compreensão dessas sentenças diferem daqueles que são ativados durante o processamento de sentenças literais; e b) a participação do HD é crucial nesse processo. A hipótese central do estudo, embora não tenha sido sinalizada pelos autores, pode ser correlacionada à coarse-code hypothesis, segundo a qual o HD seria recrutado, em termos

2 Neste ponto, faz-se necessário estabelecer uma distinção clara entre sentença e enunciado. Usualmente, enunciado corresponde ao par sentença e contexto no qual a sentença é enunciada. No primeiro experimento descrito, por não haver contextualização, emprega-se, preferencialmente, o termo sentença. 
neurológicos, a fim de garantir a correlação semântica e a coerência entre os elementos presentes nos enunciados metafóricos.

Para desenhar o experimento, foram selecionadas 63 sentenças do tipo 'Um A é um B'. Destas, 21 eram literais, como 'O golfinho é um animal', 21 metafóricas, como 'A verdade é um labirinto', e 21 anômalas, como 'As tesouras são cachorros'. Os participantes tinham de julgar, apertando botões que corresponderiam à confirmação ou à refutação, caso tivessem ou não compreendido as sentenças que lhes eram randomicamente apresentadas, enquanto imagens em fMRI eram coletadas.

Os achados revelaram que durante o processamento de sentenças com metáforas é fundamental a atuação do HE, em especial as regiões do córtex frontal inferior (BA 44 - Área de Broca) esquerdo, responsável pelo processamento semântico. Entretanto, houve também o recrutamento do HD, pela ativação do córtex frontal medial bilateral (BA 9/10), envolvido no processamento inferencial de metáforas, em especial no estabelecimento da coerência entre A e B, nas sentenças do tipo 'A verdade é um labirinto'. A essa região, em particular, são atribuídas as funções de estabelecer coerência nos enunciados e de verificar aspectos pragmáticos que devem ser levados em consideração no julgamento da aceitabilidade semântica em cada situação de uso. Evidenciou-se, também, maior ativação da região do córtex bilateral pré-frontal dorso lateral (BA 46) apenas durante o processamento das metáforas, indicando maior esforço cognitivo.

Além disso, verificou-se que a compreensão das sentenças com metáforas demandou maior tempo de processamento a fim de se atingir a coerência semântica, inclusive em relação às sentenças anômalas. Esses achados revelam que, de fato, o grau de dificuldade no processamento de metáforas é maior, se comparado aos demais enunciados.

No segundo estudo, Eviatar e Just (2006) evidenciaram os correlatos neurais ativados durante o processamento de enunciados literais, metafóricos
- apenas com metáforas convencionais, pela classificação dos autores - e irônicos. A hipótese central do estudo era a de que haveria diferenças no recrutamento de áreas neuronais acessadas na compreensão de enunciados literais, se comparados àqueles que continham metáforas e ironias, tanto em relação aos correlatos neurais ativados, quanto em relação ao tempo de processamento.

Os participantes, durante o experimento, deveriam ler pequenos textos que finalizavam com uma sentença crítica do tipo 'A é um B', como em (1).

(1) O pai pediu a Maria que ajudasse a arrumar a mesa para uma refeição. Enquanto o ajudava pondo os pratos à mesa, ela cantarolava. 0 pai disse 'você é meu raio de sol'.

Durante a leitura, imagens em fMRI eram coletadas a fim de se verificarem as regiões do cérebro ativadas durante o processamento dos enunciados que continham essas sentenças.

Os achados revelaram que, durante a leitura das metáforas, foram ativados, no HE, o giro frontal inferior, o giro temporal inferior e o córtex estriado inferior, cujas funções dizem respeito ao processo de seleção lexical e semântica, tipicamente acessados no processamento de metáforas convencionais. Com relação à participação do HD, evidenciou-se que, durante o processamento dos enunciados não literais, os giros temporais medial e superior direito foram ativados durante o processamento da ironia e o giro temporal inferior direito foi acessado durante o processamento da metáfora.

Segundo os autores, uma das hipóteses para maior ativação do HE no processamento da metáfora é a diferença entre metáforas convencionais e metáforas criativas. As primeiras são processadas mais no HE, porque, ainda segundo os autores, são tomadas como itens lexicalizados, ou seja, os enunciados metafóricos são processados como uma palavra mais longa, cujo significado é reconhecido como uma unidade lexical; já para a interpretação 
de metáforas criativas seria preciso acessar traços semânticos comuns entre os elementos A e B da sentença. Por essa razão, os achados corroboram a ideia de que metáforas lexicalizadas são processadas, predominantemente, no HE. Essa evidência sustenta a coarse-code hypothesis, ainda que essa hipótese não tenha sido apresentada no estudo.

Como durante a compreensão de metáforas houve maior ativação do HE e de regiões homólogas no HD, uma importante conclusão a que se chega neste estudo é a de que a interpretação de enunciados com linguagem figurada não é função tão somente do HD, mas uma complementação das funções do HE.

Por fim, no terceiro estudo, Prat et al. (2012) também apresentam uma análise acerca dos correlatos neurais que são ativados durante o processamento de enunciados metafóricos. O propósito da pesquisa era o de verificar como e quando o HD é recrutado para processar o enunciado. Mas o grande diferencial desse estudo foi o de identificar em que medida as diferenças individuais dos sujeitos participantes do experimento, em especial no que dizem respeito a suas habilidades de leitura, são decisivas para a ativação ou não do HD quando da interpretação de enunciados metafóricos.

Para isso, o experimento foi desenhado da seguinte maneira: os participantes visualizavam uma sentença introdutória, uma segunda sentença que indicava o contexto discursivo da compreensão e, então, a sentença crítica 'A é um B'. O sentido da sentença crítica era determinado pela sentença de contexto. Ou a sentença crítica era tida como literal, ou como metafórica, ou como irônica. Havia ainda uma quarta possibilidade, a sentença controle, em que a sentença de contexto em nada contribuía para a produção da compreensão da sentença crítica. Neste estudo, portanto, o sentido da sentença crítica dependia do entendimento dos elementos contextuais. É o que se ilustra a seguir:
Quadro 1 - Modelo de Estímulo

\begin{tabular}{|l|l|}
\hline Sentença de introdução (1) & Samanta foi a primeira de suas amigas a casar. \\
& $\begin{array}{l}\text { Contexto literal: Todos estavam excitados a respeito da linhagem } \\
\text { real de seu marido. }\end{array}$ \\
\hline $\begin{array}{l}\text { Contexto metafórico: Seu marido antecipava todos os desejos de } \\
\text { Sentença de contexto (2) }\end{array}$ & $\begin{array}{l}\text { Contexto irônico: Seu marido nunca a ajudava nos afazeres da } \\
\text { casa. }\end{array}$ \\
\hline Contexto neutro: Samanta conheceu seu marido no Ensino Médio. \\
\hline Sentença crítico (3) & Samanta disse: Ele é um príncipe. \\
\hline
\end{tabular}

Fonte: Prat et al. (2012, p. 5).

Antes de participarem do experimento, os voluntários eram submetidos a testes de leitura ${ }^{3}$, em que se verificou seu domínio lexical, ou seja, o potencial de memória lexical acessível durante o processamento da leitura. Seu desempenho no teste de leitura associado aos resultados obtidos no experimento foi fundamental para a manutenção da tese central do estudo: as características individuais têm papel central na necessidade de recrutamento do HD no processamento de enunciados com linguagem figurada, tais como a metáfora e a ironia. Ou seja, esse estudo corroborou a premissa central da dynamic spillover hypothesis.

Os achados revelaram que, à medida que o contexto apresentado induzisse à compreensão do enunciado crítico como uma metáfora ou uma ironia, ou seja, a dificuldade dos enunciados aumentasse, aumentava também a ativação da rede de compreensão da linguagem bilateralmente distribuída. Portanto, o HD era progressivamente envolvido na compreensão de metáforas e ironias quando a dificuldade de processamento aumentava.

3 Reading Span Test (Daneman e Carpenter, 1980), the Nelson-Denny Reading Test (Brown, Fishco Hanna, 1993) e o Edinburgh Handedness Inventory (Oldfield, 1971). 
Além disso, evidenciou-se correlação negativa entre os scores individuais nos testes de leitura e a ativação de regiões do HD, em especial o giro frontal inferior direito, o giro frontal medial direito e região frontopolar direita - regiões homólogas às áreas da linguagem no HD. Assim, o experimento corroborou a hipótese de que as características individuais são decisivas no reconhecimento da dificuldade de um enunciado: quanto maior a dificuldade, maior a ativação do HD. Bons leitores, segundo essa hipótese, ativariam, portanto, em menor proporção as regiões análogas à compreensão no HD.
Justamente na interpretação das metáforas, indivíduos com pouco vocabulário ativaram em maior escala os giros bilaterais frontais e mediais, responsáveis pela recuperação de dados na memória de trabalho, e as regiões do córtex anterior cingulado, responsáveis pela atenção e monitoramento de tomadas de decisões, quando era necessário compreender o enunciado crítico. Em contrapartida, os bons leitores ativaram essas regiões em menor escala e somente durante a fase de contextualização.

O Quadro 2 a seguir mostra, resumidamente, os correlatos neurais dos achados e as conclusões a que chegaram os estudos.

Quadro 2 - Resumo dos achados em neuroimagem

\begin{tabular}{|c|c|c|c|c|}
\hline & Shibata et al. (2007) & \multicolumn{2}{|c|}{ Eviatar e Just (2006) } & Prat et al. (2012) \\
\hline Correlatos neurais & $\begin{array}{l}\text { - córtex bilateral pré-frontal dorso lateral } \\
\text { - córtex frontal inferior esquerdo } \\
\text { - córtex frontal medial bilateral }\end{array}$ & $\begin{array}{l}\text { METÁFORAS: } \\
\text { - giro frontal inferior esquerdo } \\
\text { - giro temporal inferior esquerdo } \\
\text { - córtex estriado inferior esquerdo } \\
\text { - giro temporal inferior direito }\end{array}$ & $\begin{array}{l}\text { IRONIAS: } \\
\text { - giro temporal medial direito } \\
\text { - giro temporal superior direito }\end{array}$ & $\begin{array}{l}\text { - giro frontal inferior direito } \\
\text { - giro frontal medial direito } \\
\text { - região frontopolar direita }\end{array}$ \\
\hline Conclusões & $\begin{array}{l}\text { - Os enunciados metafóricos demandam } \\
\text { tanto maior tempo quanto maior custo } \\
\text { de processamento; } \\
\text { - Os enunciados metafóricos são } \\
\text { processados essencialmente pelo } \\
\text { HE, mas o HD é recrutado quando há } \\
\text { necessidade de complementação do } \\
\text { sentido, de correlação entre conceitos e } \\
\text { de estabelecimento da coerência entre } \\
\text { A e B, em 'Um A é um B'. }\end{array}$ & \multicolumn{2}{|c|}{$\begin{array}{l}\text { - Os enunciados com metáforas cristalizadas são interpretados predominantemente } \\
\text { no HE, mas com a participação do HD. Uma das razões é que esses enunciados são } \\
\text { reconhecidos como lexicalizados, daí a participação do HE. } \\
\text { - A compreensão de ironias exige maior recrutamento do HD. }\end{array}$} & $\begin{array}{l}\text { - Os enunciados metafóricos e } \\
\text { irônicos demandam maior tempo de } \\
\text { processamento. } \\
\text { - A busca por traços semânticos em } \\
\text { comum entre alvo e veículo não } \\
\text { depende apenas da natureza semântica } \\
\text { dos itens em questão. Depende também } \\
\text { da integração da sobreposição dada } \\
\text { pelo contexto. } \\
\text { - Maus leitores recrutam com mais } \\
\text { facilidade o HD, porque mais } \\
\text { rapidamente se esgotam as capacidades } \\
\text { de processamento do HE. }\end{array}$ \\
\hline Hipótese central & Coarse-code hypothesis & \multicolumn{2}{|l|}{ Coarse-code hypothesis } & Dynamic spillover hypothesis \\
\hline
\end{tabular}

Fonte: A autora 
Esses achados induzem a, pelo menos, duas considerações. Em primeiro lugar, ainda não há consenso em relação à construção de um modelo de processamento cognitivo de metáforas, que descreva e explique as funções do HD. Em segundo lugar, ainda que haja diferenças nos achados, parece razoável a hipótese de que as regiões homólogas à linguagem no HD sejam recrutadas em razão das características da metáfora apresentada no enunciado e da demanda de esforço de processamento, mas, principalmente, pelas aptidões individuais dos sujeitos em relação às habilidades de leitura de que dispõem.

\section{Das possibilidades explanatórias: a relevância da Pragmática}

Esta seção tem o objetivo de ilustrar as especificidades do modelo pragmático da Teoria da Relevância (TR), tal como desenhado por Sperber e Wilson (1986; 2008) e Wilson e Sperber (2012), no que dizem respeito ao potencial explanatório da natureza do processamento cognitivo da metáfora. Pretende-se, portanto, apresentar a metáfora desenhada sob o paradigma da Pragmática.

A TR absorveu o modelo de Teoria das Implicaturas Conversacionais, proposto por Grice (1975) ${ }^{4}$, e formulou uma hipótese explicativa mais complexa para o fenômeno da produção de inferências em linguagem natural, explicando-as não apenas do ponto de vista lógico, mas, em especial, sob o aspecto cognitivo. Tal proposta tem servido de pano de fundo para muitos estudos em linguagem natural, tendo como base a cognição humana.

\footnotetext{
${ }^{4}$ A Teoria das Implicaturas de Grice (TIG), mesmo não abordando especificamente uma teoria da metáfora, mas uma teoria geral da comunicação humana, tem como ponto de partida a tentativa de descrever e explicar de que modo se dá a produção de implicaturas durante as situações de comunicação, estabelecendo uma distinção entre o que é dito e o que é implicado.
}

A TR fundamenta-se no pressuposto de que o ouvinte fará um esforço de atenção, de memória e de compreensão, a fim de compreender aquilo que julgar relevante. Assim, para garantir a atenção em um enunciado, é preciso que a comunicação enriqueça ou altere o ambiente cognitivo, por meio do acréscimo de novos conhecimentos e crenças, ou pelo cancelamento de velhas crenças, ou, ainda, por uma pequena mudança no grau de reconhecimento e de confiança em velhas crenças. Em todas as situações de comunicação verbal, tanto as mais simplificadas quanto as mais complexas, o falante intencionará garantir que o enunciado que quer expressar garanta efeitos contextuais suficientes a ponto de prender a atenção do ouvinte. Nesse aspecto fundamenta-se a tese central da TR, delineada pelo Princípio da Relevância (PR), que é apresentado da seguinte maneira: "Todo ato de comunicação ostensiva comunica a presunção de sua própria relevância ótima" (SPERBER; WILSON, 1986, p. 158). Ou seja, as pessoas dirigem sua atenção àquilo que lhes pareça relevante.

Subjacentes ao Princípio da Relevância estão as definições a seguir:

(a) quanto maior o efeito cognitivo obtido pelo processamento de alguma informação, maior a relevância para o indivíduo que a processa;

(b) quanto menor o esforço envolvido no processamento de alguma informação, maior sua relevância para o indivíduo que a processa.

Nas versões recentes da teoria (SPERBER; WILSON, 2008; WILSON; SPERBER, 2012), os autores aprofundaram o potencial explicativo dos fundamentos da TR, ao complexificar o entendimento da produção de inferências.

A produção de sentido de um enunciado de qualquer natureza, inclusive metafórica, passou a ser explicada como consequência de um ajuste conceitual de elementos contextuais, além do estreitamento (narrowing) ou alargamento (broadening) de um conceito. 
Como resultado da associação dessas propriedades, são produzidos os conceitos $a d$ hoc ${ }^{5}$, específicos para cada contexto de comunicação.

Sob esse paradigma, para se interpretar o enunciado apresentado em (1):

(1) Você é meu raio de sol.

e inferir, obtendo-se relevância ótima, algo como

(1a) Você é a alegria da minha vida.

deve-se considerar que RAIO DE SOL, na especificidade desse enunciado, não se refere a um raio de sol propriamente dito. Portanto, nesse caso, temse o significado ad hoc RAIO DE SOL*, para o qual o conceito A ALEGRIA DA MINHA VIDA constitui-se um traço emergente nesse contexto, enquanto outros, como FONTE DE LUZ e FONTE DE CALOR, por exemplo, devem ser descartados.

Por serem decorrentes do processo de produção de implicaturas em um contexto específico, os conceitos ad hoc serão produzidos caso o ouvinte seja induzido pela busca da relevância máxima. Em (1), houve um alargamento (broadening) de significado: RAIO DE SOL deve ser entendido desconsiderando-se alguns dos sentidos específicos de RAIO DE SOL em sua acepção literal, para então se agregarem conceitos que envolvem descrições e avaliações de comportamentos e emoções de seres humanos.

Sperber e Wilson argumentam, ainda, que no processo de produção de conceitos ad hoc, em tese, o ouvinte parte do pressuposto de que o enunciado comunicado pelo falante, em razão do PR, tenha sido produzido com uma garantia de relevância. Ora, se o falante, de modo geral, intenciona comunicar um pensamento complexo, formado por proposições mais salientes e cons-

\footnotetext{
5 Conceitos lexicais são expressos por versaletes: RAIO DE SOL; já os conceitos ad hoc, por versaletes e asterisco: RAIO DE SOL*
}

cientes que outras, ao ouvinte cabe a tarefa de reconhecer justamente que aspectos mais salientes, ou propriedades emergentes, o falante quer implicar. Assim, o ouvinte deve computar em ordem de acessibilidade ${ }^{6}$ as propriedades emergentes que devem ser mais relevantes para a compreensão do enunciado.

Em enunciados metafóricos, segundo os autores, o ouvinte terá maior responsabilidade pela produção de inferências, já que lhe é permitida, além da exploração do contexto imediato e de seu conhecimento prévio, maior liberdade em acessar uma área mais ampla de conhecimento e, por isso, gerar um maior número de implicaturas para esses enunciados.

Wilson e Sperber (2012) definem esse processamento da seguinte maneira:

O ouvinte desenvolve (em paralelo) tentativas de interpretação dos componentes explícitos e implícitos do significado proposto pelo falante, encerra-as quando esses se unem juntamente com o sentido contextualmente explicitado, podendo, então, derivar as implicaturas conclusivas. (WILSON; SPERBER, 2012, texto digital)

Evidentemente, há, sob esse paradigma, metáforas mais fáceis de se interpretar, já que geram um menor número de implicaturas, e outras que, por sua vez, exigem um maior número de implicaturas para seu processamento, ainda que produzam maiores efeitos contextuais, devido a maior liberdade de processamento. As primeiras, por sua natureza aparentemente simplificada, são entendidas como metáforas convencionais. É o caso de (1), por exemplo. Já as últimas são tidas como metáforas criativas, cuja relevância dependerá da produção de várias implicaturas, mais fracas, como veremos mais adiante. Porém, em contrapartida, decorrente delas serão produzidos maiores efeitos contextuais adicionais, em decorrência de seu efeito poético (cf. SPERBER e WILSON, 2008, p. 100).

${ }^{6}$ A noção de acessibilidade, aqui pretendida, refere-se às partes de informação que estão mais disponíveis para os interlocutores e próximas do contexto em que se dá a comunicação. 
Nesta seção pretendeu-se apresentar brevemente os pressupostos teóricos da TR, no intuito de se evidenciar de que modo pode ser desenhada a metáfora sob o paradigma de uma teoria de natureza pragmática.

\section{Por uma interface possível: ampliação do potencial descritivo e explanatório de uma teoria da metáfora}

Pretende-se neste estudo ilustrar que no âmbito da interface complexifica-se o potencial descritivo e explanatório de uma abordagem teórica da metáfora. Nesta seção, portanto, para fins de ilustração, a metáfora será desenhada na interface entre Neurociências e Pragmática.

Entretanto, reconhece-se a complexidade de uma proposta desse tipo, já que estudos interdisciplinares requerem ajustes metateóricos e adequações no desenho dos objetos em estudo. Poeppel e Embick (2005) já apontavam alguns dos problemas decorrentes de propostas dessa natureza: a) o problema da incompatibilidade granular, segundo o qual os objetos de investigação, em áreas interdisciplinares, não compartilham, necessariamente, a mesma granularidade. É o caso deste estudo, pois o escopo da Pragmática, grosso modo, é o enunciado, enquanto as Neurociências lidam com neurônios e funções corticais; b) o problema da incomensurabilidade ontológica, segundo o qual, ao se construírem objetos de investigação em certos campos científicos, não se pode avaliá-los fora do escopo dos campos nos quais foram concebidos.

A Metateoria das Interfaces (2007) pode apontar para uma possível solução para esse impasse: é preciso que se construam objetos terceiros, frutos da aproximação entre as disciplinas, que partilhem propriedades desenhadas no escopo das disciplinas (cf. COSTA, 2007, p. 348). Assim, a natureza ontológica do objeto, neste caso a metáfora, é multivalente e multiforme. A seguir, ilustra-se essa proposta.

Como já se disse, a produção de conceitos ad hoc para o processamento inferencial dos enunciados depende da acessibilidade das propriedades emergentes que partilham os elementos em contraste nos enunciados metafóricos. Os mais relevantes serão empregados para a produção das inferências.

Tomemos como exemplo os enunciados a seguir, utilizados em um dos experimentos descritos anteriormente (SHIBATA et al., 2007, p. 100):

(2) A memória é um armazém.

(3) Entusiasmo é lava.

A fim de produzir a compreensão de ambos os enunciados, o ouvinte precisa acessar traços emergentes de ARMAZÉM e LAVA que se associem aos conceitos de MEMÓRIA e ENTUSIASMO, respectivamente.

Aparentemente, parece que de (2) se acessa uma implicatura mais forte, algo como em (2a):

(2a) A memória é um local onde se guardam coisas de todos os tipos.

Já de (3) decorrem implicaturas mais fracas:

(3a) Entusiasmo é torrente.

(3b) Entusiasmo é descontrole.

(3c) Entusiasmo com o tempo esfria.

(3d) Entusiasmo é destruição.

Quanto maior o número de implicaturas acessadas, maior o esforço cognitivo para processar a metáfora. É o caso das metáforas criativas, para as quais há necessidade de maior geração de implicaturas fracas. No caso de metáforas convencionais, como há apenas uma implicatura forte a ser acessada, menor o esforço de processamento. Temos, então, em (2), ARMAZÉM*; em (3), porém, LAVA*, LAVA**, LAVA*** e LAVA****.

Os dados em neuroimagem confirmam essa explicação, pois os correlatos neurais para o processamento cognitivo da metáfora são descritos nos 
seguintes termos: durante o processamento de enunciados com metáforas, além de áreas como giro frontal inferior esquerdo e giro temporal inferior esquerdo, comumente recrutadas no HE para o processamento de linguagem natural, também o são as regiões análogas no HD, principalmente para o caso de metáforas reconhecidas como criativas, como em (3). Portanto, de acordo a coarse-code hypothesys, metáforas convencionais, como em (2), por terem sentido cristalizado, preferencialmente ativam regiões do HE. Quando o grau de dificuldade aumenta e há necessidade de estabelecer correlações entre traços semânticos entre elementos que aparentemente não compartilham esses traços, regiões homólogas ao HE são também ativadas no HD, como em (3). Isso significa que o PR explica os achados: quando mais áreas neurais são ativadas, mais conceitos $a d$ hoc são produzidos e, portanto, maior o custo de processamento.

Sob o ponto de vista da dynamic spillover hypothesis (cf. PRAT et al., 2012), o HD será recrutado no processamento de metáforas, dependendo tanto do contexto de uso, quanto das características cognitivas do ouvinte. Quanto maior seu conhecimento prévio, menor a necessidade de esforço de processamento e menor, portanto, a necessidade de ativação de regiões do HD. Indivíduos com pouco vocabulário ativaram os giros bilaterais frontais e mediais, responsáveis pela recuperação de dados na memória de trabalho. Como Sperber e Wilson argumentam, o ouvinte deve reconhecer quais são os aspectos mais salientes, ou as propriedades emergentes que o faltante quer implicar, dado o contexto de comunicação.

É o caso de (4), também utilizado nos testes descritos em PRAT et al. (2012):

\section{(4) Ele é um príncipe.}

Quais as propriedades emergentes de PRÍNCIPE a serem acessadas para a produção de inferências como em (4a), (4b) e (4c), para o contexto que evoca o sentido literal, ou uma metáfora, ou uma ironia, respectivamente?

(4a) Ele é o filho da rainha.

(4b) Ele é gentil e amoroso.

(4c) Ele não é um príncipe.

Tanto o contexto de produção do enunciado, quanto os conhecimentos prévios do ouvinte são variáveis que determinam se haverá maior necessidade de recrutamento de regiões corticais para o processamento das metáforas. Mas a produção de conceitos ad hoc, PRÍNCIPE*, em (4a), ou PRÍNCIPE*, em (4b), e PRÍNCIPE*, em (4c), dependerá do conhecimento prévio do ouvinte.

Do ponto de vista neurocientífico, baixos scores em leitura correspondem à necessidade de maior recrutamento do HD, já que muito rapidamente se esgotam os recursos de processamento do HE. Do ponto de vista pragmático, a produção de conceitos ad hoc tem correlação direta com os conhecimentos prévios disponíveis pelo próprio ouvinte para serem empregados na escolha dos traços emergentes mais relevantes em cada enunciado. Do ponto de vista da interface, quanto maior o custo de processamento para a produção de conceitos ad hoc para os enunciados com metáforas, maior a necessidade de recrutamento do HD.

\section{Considerações finais}

Pretendeu-se neste estudo propor uma abordagem teórica da metáfora a partir do diálogo interdisciplinar, a fim de se ampliar o potencial descritivo e explanatório de uma possível teoria da metáfora.

Em razão da natureza complexa do objeto de investigação aqui abordado, propôs-se que também fossem complexificados os fundamentos teóricos de uma abordagem na interface entre disciplinas, quais sejam Linguística Pragmática e Neurociências. Assumiu-se, assim, duas premissas que 
sustentam as reflexões aqui pretendidas: as Neurociências, por sua natureza, têm potencial descritivo, já que clarificam as estruturas neurais recrutadas durante o processo de compreensão das metáforas; a Pragmática, via TR, têm potencial explanatório, que justifica a natureza dos achados em fMRI.

Ao se desenhar a metáfora na interface, concluiu-se que, de fato, as relações interdisciplinares, como sugeridas pela Metateoria das Interfaces (COSTA, 2007), podem contribuir fortemente para o desenvolvimento de uma teoria da metáfora nas fronteiras interdisciplinares, sob novos enfoques e paradigmas epistemológicos. Complexificam-se, assim, a descrição e a explicação de um fenômeno linguístico desenhado na interface entre Pragmática e Neurociências.

Evidentemente, o viés teórico tal como desenhado neste estudo não pode se esgotar com as reflexões propostas. Isso porque, se assim o fosse, haveria uma contradição ontológica no argumento central aqui sustentado: se novas interfaces podem ser estabelecidas, novos objetos podem ser construídos, assumindo novas propriedades. Assim, novos argumentos e paradigmas também podem se constituir a partir dos estudos nas interfaces.

\section{Referências}

CARSTON, Robin. Metaphor, ad hoc concepts and word meaning. UCL working papers in linguistic, v. 14, p. 83-105, 2002.

CARSTON, Robin; POWELL, George. Relevance Theory: New Directions and Developments. In: LEPORE, Ernest; SMITH, Barry C. The Oxford Handbook of Philosophy of Language. London: Oxford University Press, 2006.

COSTA, Jorge Campos da. The sciences of language: communication, cognition and computation. In: AUDY, J.; MOROSINI, M. Inovação e Interdisciplinaridade na Universidade. Porto Alegre: EDIPUCRS, 2007. p. 345-360.

EVIATAR, Zohar; JUST, Marcel A. Brain correlates for discourse processing: an fMRI investigation of irony and conventional metaphor comprehension. Neuropsychologia, v. 44, n. 12, p. 2348-2359, 2006. http://dx.doi.org/10.1016/j.neuropsychologia.2006.05.007
FERSTL, Evelyn C. The functional neuroanatomy of text comprehension: what's the story so far? In: SCHMALHOFER, Franz; PERFETTI, Charles A. Higher Level Language in the Brain: Inference and Comprehension Processes. London: Psychology Press, 2012. p. 53-102.

GRICE, Paul. Mening. In: STEINBERG, Danny; JAKOBOVITS, Leon. Semantics: an interdisciplinary reader in philosophy, linguistics and psychology. Cambridge: Cambridge University Press, 1975. p. 52-65.

MASON, Robert A.; WILLIAMS, Diane L.; KANA, Rajesh K.; MINSHEW, Nancy; JUST, Marcel A. Theory of Mind disruption and recruitment of the right hemisphere during narrative comprehension in autism. Neuropsychologia, v. 46, p. 269-280, 2008. http://dx.doi. org/10.1016/j.neuropsychologia.2007.07.018

NOVECK, Ira; BIANCO, Maryse; CASTRY, Alain. The costs and benefits of metaphor. Metaphor and Symbol, v. 16, p. 109-121, 2001.

POEPPEL, David; EMBICK, David. Defining the relation between linguistics and neuroscience. In: CUTLER, A. (Ed.). Twenty-First Century Psycholinguistics: Four Cornerstones. Mahwah, NJ: Erlbaum, 2005, p. 103-118.

PRAT, Chantel S.; MASON, Robert A.; JUST, Marcel A. Individual differences in the neural basis of causal inferencing. Brain and Language, v. 116, p. 1-13, 2011. http://dx.doi. org/10.1016/j.bandl.2010.08.004

PRAT, Chantel S.; MASON, Robert A.; JUST, Marcel A. An fMRI investigation of analogical mapping in metaphor comprehension: The influence of context and individual cognitive capacities on processing demands. Journal of Experimental Psychology: Learning, Memory and Cognition, v. 38, p. 282-294, 2012. http://dx.doi.org/10.1037/a0026037

SAXE, Rebecca; KANWISHER, Nancy. People thinking about thinking people: the role of the temporo-parietal junction in "theory of mind". NeuroImage, v. 19, p. 1835-1842, 2003 http://dx.doi.org/10.1016/S1053-8119(03)00230-1

SEARLE, John R. (1982). Metaphor. In: DAVIS, S. Pragmatics: a reader. New York: Oxford University Press, 1991. p. 519-539.

SHIBATA, Midori; ABE, JJun-ichi; TERAO, Atsushi; MIYAMOTO, Tamaki. Neural mechanisms involved in the comprehension of metaphoric and literal sentences: An fMRI study. Brain Research, 1166, p. 92-102, 2007. http://dx.doi.org/10.1016/j.brainres.2007.06.040

SPERBER, Dan; WILSON, Deirdre. Relevance: communication \& cognition. 2. ed Cambridge: Blackwell, 1986. 
SPERBER, Dan; WILSON, Deirdre. Loose talk. In: DAVIS, S. Pragmatics: a reader. New York: Oxford University Press, 1991. p. 540-549.

SPERBER, Dan; WILSON, Deirdre. A deflationary account of metaphors. In: Gibbs, R. (Ed.). The Cambridge Handbook of Metaphor and Thought. Cambridge: Cambridge University Press, 2008, p. 84-105. http://dx.doi.org/10.1017/CB09780511816802

TENDAHL, Markus; GIBBS JR., Raymond W. Complementary perspectives on metaphor: cognitive linguistics and relevance theory. Journal of Pragmatics, v. 40, p. 1823-1864, 2008. http://dx.doi.org/10.1016/j.pragma.2008.02.001

WILSON, Deidre; CARSTON, Robin. Metaphor, Relevance and the 'Emergent Property' Issue. In: Mind and Language, v. 21, n. 3, p. 404-433, 2006. http://dx.doi.org/10.1111/ j.1468-0017.2006.00284.x

WILSON, Deidre; SPERBER, Dan. Meaning and Relevance. Cambridge: Cambridge University Press, 2012. E-book.

Recebido em 01 de dezembro de 2014 Aceito em 15 de abril de 2015 . 